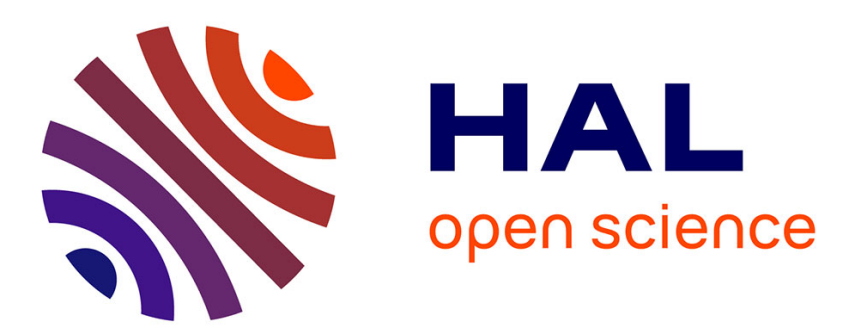

\title{
A 3D Super-elastic Model for Shape Memory Alloys Taking into account Progressive strain under Cyclic Loadings
}

Luc Saint-Sulpice, Shabnam Arbab-Chirani, Sylvain Calloch

\section{- To cite this version:}

Luc Saint-Sulpice, Shabnam Arbab-Chirani, Sylvain Calloch. A 3D Super-elastic Model for Shape Memory Alloys Taking into account Progressive strain under Cyclic Loadings. Mechanics of Materials, 2009, 41, pp.12-26. 10.1016/j.mechmat.2008.07.004 . hal-00449131

\section{HAL Id: hal-00449131 https://hal.science/hal-00449131}

Submitted on 11 Feb 2010

HAL is a multi-disciplinary open access archive for the deposit and dissemination of scientific research documents, whether they are published or not. The documents may come from teaching and research institutions in France or abroad, or from public or private research centers.
L'archive ouverte pluridisciplinaire HAL, est destinée au dépôt et à la diffusion de documents scientifiques de niveau recherche, publiés ou non, émanant des établissements d'enseignement et de recherche français ou étrangers, des laboratoires publics ou privés. 
A 3D Cyclic Super-elastic Model

For Shape Memory Alloys

Taking Into Account Ratchetting Effect

Luc Saint-Sulpice $^{a}$, Shabnam Arbab Chirani ${ }^{b, a}$, Sylvain Calloch $^{a 1}$

${ }^{a}$ Pôle de Mécanique Brestois, Laboratoire de Mécanique des Structures Navales, ENSIETA 2 rue François Verny, F-29806 Brest Cedex 9, FRANCE

${ }^{b}$ Pôle de Mécanique Brestois, Laboratoire de Recherche en Mécatronique, ENIB

Technopôle Brest-Iroise, F-29280 Plouzané, FRANCE

\footnotetext{
${ }^{1}$ Contact: Fax: +332983487 23, E-mail: sylvain.calloch@ensieta.fr
} 


\section{Contents}

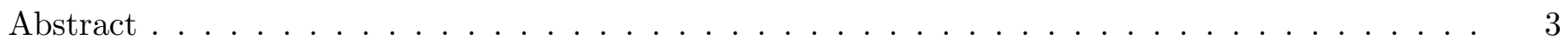

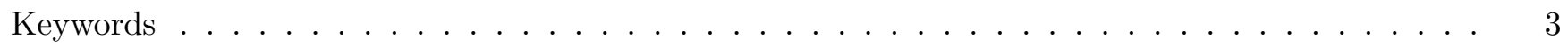

$\begin{array}{ll}\text { Introduction } & 4\end{array}$

1 Experimental investigations under uniaxial loading characterizing the mechanical behavior of the material

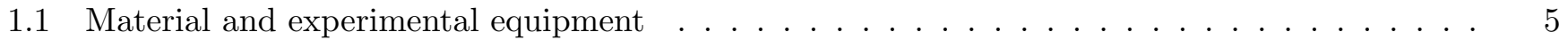

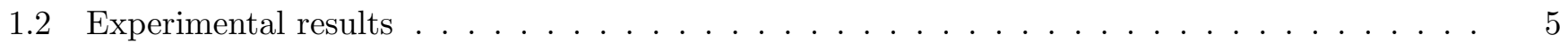

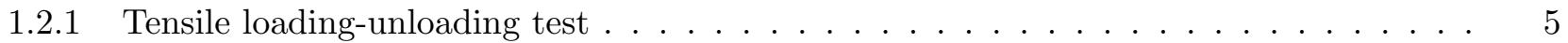

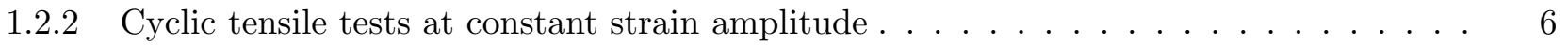

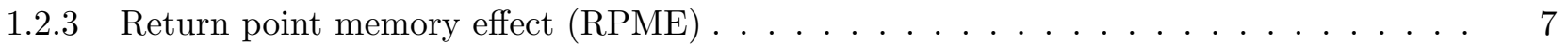

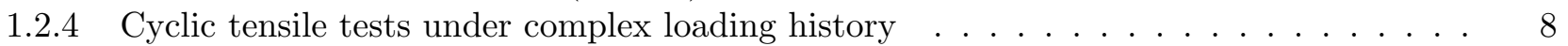

1.2.5 Evolution of residual strain during a thermal flash . . . . . . . . . . . . . . . 9

2 3D Model for super-elastic behavior of SMA under cyclic loading 10

2.1 Strain decomposition and definition of internal variables . . . . . . . . . . . . . . 10

2.2 Forward and reverse transformation surfaces . . . . . . . . . . . . . . . . . . . . . . 10

2.3 Martensite volume fraction . . . . . . . . . . . . . . . . . . . . . 11

2.4 Transformation strain evolution . . . . . . . . . . . . . . . . . . . . 11

2.5 Forward and reverse transformation surfaces evolution during phase transformation . . . . . . 12

2.5.1 Return point memory effect . . . . . . . . . . . . . . . . . . . . 12

2.5.2 Progressive strain under cyclic loading . . . . . . . . . . . . . . . . . 15

2.5.3 Progressive strain under complex loading history . . . . . . . . . . . . . . . . 15

3 Numerical results $\quad 17$

3.1 Material parameters identification for studied $\mathrm{Cu}-\mathrm{Al}-\mathrm{Be} \mathrm{SMA} \ldots \ldots \ldots \ldots$

3.3 Simulation of multiaxial non-proportional cyclic loading . . . . . . . . . . . . . . . 17

3.2 Simulation of proportional cyclic loading . . . . . . . . . . . . . . . . . . . . 18

$\begin{array}{ll}\text { Conclusions } & 20\end{array}$

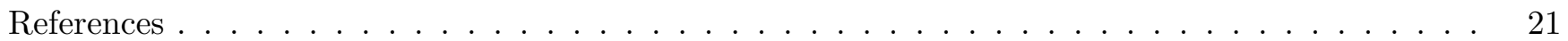




\title{
A 3D Cyclic Super-elastic Model
}

\section{For Shape Memory Alloys \\ Taking Into Account Ratchetting Effect}

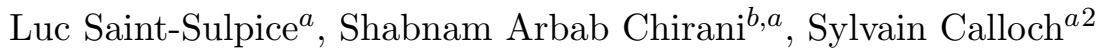 \\ ${ }^{a}$ Pôle de Mécanique Brestois, Laboratoire de Mécanique des Structures Navales, ENSIETA \\ 2 rue François Verny, F-29806 Brest Cedex 9, FRANCE \\ ${ }^{b}$ Pôle de Mécanique Brestois, Laboratoire de Recherche en Mécatronique, ENIB \\ Technopôle Brest-Iroise, F-29280 Plouzané, FRANCE
}

\begin{abstract}
This paper concerns the mechanical behavior of super-elastic shape memory alloys under cyclic loading. Sometimes, as shown by many experimental observations, a permanent inelastic strain occurs and increases with the number of cycles. A series of cyclic tests has been carried out and used to develop a 3D macroscopic model for super-elasticity of SMA able to describe the evolution of permanent inelastic strain during cycling.
\end{abstract}

Keywords: Super-elasticity; Experimental results; Macroscopic model; Residual strain evolution; Nonproportional cyclic loading.

\footnotetext{
${ }^{2}$ Contact: Fax: +332983487 23, E-mail: sylvain.calloch@ensieta.fr
} 


\section{Introduction}

The specific thermo-mechanical behavior of Shape Memory Alloys (SMA) is due to a solid-solid phase transformation called martensitic transformation. According to steels, the high and low temperature phases are called austenitic and martensitic phases, respectively. The martensitic transformation in SMA consists mainly in a shear, without volume change, which can be activated either by stress or temperature. Among the various aspects in thermo-mechanical behavior of SMA (i.e., super-elasticity, pseudo-plasticity, one-way memory effect, two-way memory effect, ...) only super-elasticity is considered in this work.

In this case, the martensitic transformation is only stress induced whereas the temperature remains constant and greater than the austenite finish temperature, $A_{f}^{0}$. Super-elasticity of SMA is generally characterized by, on one hand, a typical hysteretic behavior and, on the other hand, fully reversible phase transformation (i.e., the transformation strain is totally recoverable when the stress is removed). Sometimes, as shown by many experimental observations, the stress-strain super-elastic loop is not closed and a permanent inelastic strain remains after unloading. Moreover, if the SMA is subjected to a cyclic loading, the permanent inelastic strain increases until a stable value after a certain number of cycles. This particular behavior of super-elastic SMA under cyclic loading is sometimes called "rachetting effect" according to the mechanical behavior of classic metallic alloys under cyclic loading.

Ratchetting (i.e., the progressive inelastic deformation observed under cyclic loading on (visco)-plastic material) has received considerable attention over the last thirty years. Among the great number of investigations, very few studies concern the case of super-elastic SMA under cyclic loading. Nevertheless, some mechanical models taking into account the permanent strain in super-elastic SMA have been recently proposed in the literature. In all cases, the authors introduced a supplementary internal variable representing permanent inelastic strain in addition to the transformation and elastic strains. This internal variable can be closely related to the classic plastic strain used in plasticity framework.

In this work, we propose a new three-dimensional macroscopic super-elasticity model able to describe kinetics of permanent strain under general cyclic loading (i.e., multi-axial non-proportional cyclic loading) without introducing a permanent inelastic strain variable. Only, a transformation strain is considered and an ad hoc kinetic evolution of martensitic transformation is proposed to take into account the main effects observed in super-elastic behavior of SMA under cyclic loading. So, the proposed constitutive equations permit to reproduce the super-elasticity, the return point memory effect, the tension-compression asymmetry and the evolution of permanent strain under multiaxial cyclic loading.

The present paper organized in three main sections. In the first one, a large experimental database is presented concerning the super-elastic behavior of a $\mathrm{Cu}$-Al-Be polycrystalline SMA. In the second section, the constitutive equations of the 3D macroscopic model are described in detail. In the last section, some comparisons between experimental results and simulations show the validity of the proposed model. 


\section{Experimental investigations under uniaxial loading characterizing the mechanical behavior of the material}

\subsection{Material and experimental equipment}

The material used for the tests is a $\mathrm{Cu}-\mathrm{Al}-\mathrm{Be}$ polycrystalline SMA (Cu: 87\%at, Al: 11\%at, Be: $2 \%$ at) provided by Nimesis society (France). The material is available as wires of $1.4 \mathrm{~mm}$ diameter. All specimen were heat treated at $650^{\circ} \mathrm{C}$ for twenty minutes minutes in atmospheric air and quenched in boiling water during one hour. The four characteristic transformation temperatures were determined using electric resistivity measurements. Figure 1 shows the evolution of the resistivity during a thermal cycle. The temperatures $M_{s}^{0}, M_{f}^{0}, A_{s}^{0}$ and $A_{f}^{0}$ of the concerned alloy are given in table 1 . So, the heat-treated alloy exhibits a super-elastic behavior at room temperature.

\begin{tabular}{cccc}
\hline$M_{s}^{0}$ & $M_{f}^{0}$ & $A_{s}^{0}$ & $A_{f}^{0}$ \\
$-22.5^{\circ} \mathrm{C}$ & $-35.5^{\circ} \mathrm{C}$ & $-24^{\circ} \mathrm{C}$ & $-10.5^{\circ} \mathrm{C}$ \\
\hline
\end{tabular}

Table 1: Characteristic transformation temperatures of the $\mathrm{Cu}-\mathrm{Al}-\mathrm{Be}$ SMA.

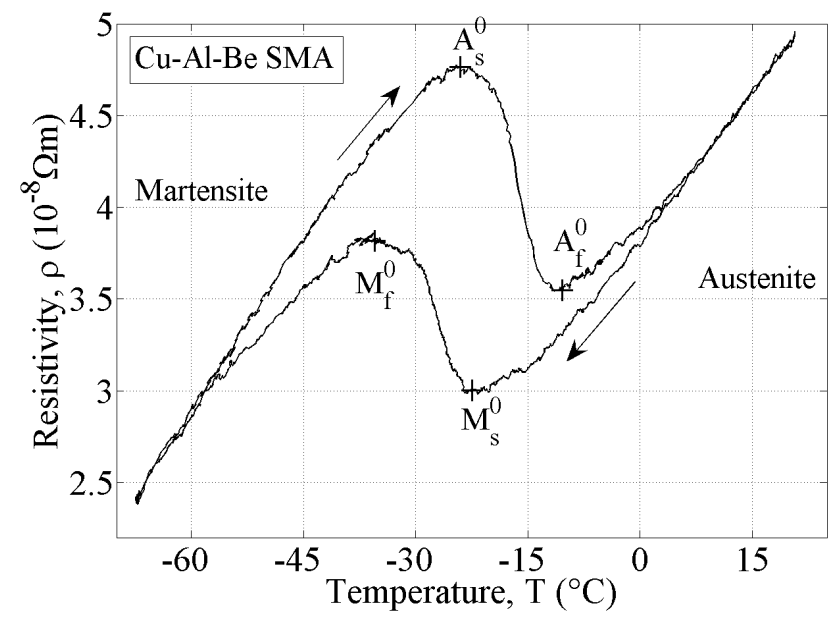

Figure 1: Determination of characteristic transformation temperatures of the $\mathrm{Cu}-\mathrm{Al}-\mathrm{Be} \mathrm{SMA}$ by resistivity measurements.

All the tests have been performed on an electro-mechanical Zwick testing machine operating in axial strain control $\left(\varepsilon=10^{-4} \mathrm{~s}^{-1}\right)$ at room temperature. A $15-\mathrm{mm}$ extensometer has been used to measure axial strain. Axial stress has been obtained using an uniaxial load cell.

\subsection{Experimental results}

A series of uniaxial tests has been performed to characterize the mechanical behavior of the material.

\subsubsection{Tensile loading-unloading test}

First, the mechanical behavior under tensile loadingunloading has been studied. A specimen has been deformed until a maximum strain of $4 \%$ then unloaded until zero stress. Figure 2 shows the corresponding strain-stress curve. After exceeding the yield stress, the forward transformation takes place and the reverse transformation occurs just after the beginning of the unloading. At the end of the unloading (i.e., zero stress) a residual strain, $\varepsilon^{r}$, of $0.6 \%(0.2 \%)$ remains.

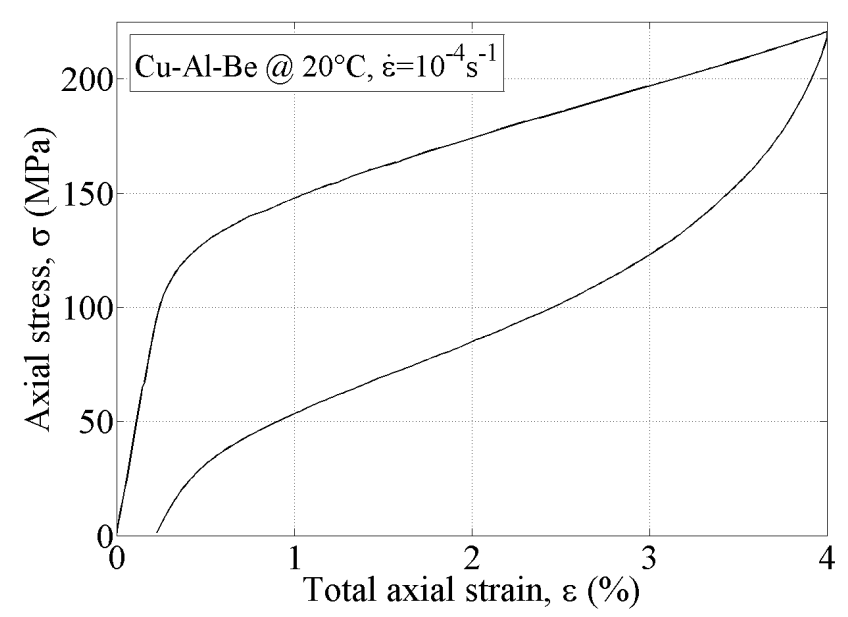

Figure 2: Stress-strain curve under tensile loadingunloading at room temperature. 


\subsubsection{Cyclic tensile tests at constant strain amplitude}

The cyclic behavior of the material has been characterized with a series of cyclic tensile tests at constant strain amplitude. Four levels of strain amplitude have been considered (1\%,2\%,3\% and 4\%). Figure 3a-d show the corresponding strain-stress responses. Some common observations can be made on these experimental results. At each time, the residual strain, $\varepsilon^{r}$, increases with the number of cycles until a saturated value. Figure 4 shows the evolution of residual strain, $\varepsilon^{r}$, versus the number of cycles, $N$. The saturated value depends on the strain amplitude. Greater the strain amplitude is, greater the saturated residual strain is. From a phenomenological point of view, this progressive deformation under cyclic loading is very similar to ratchetting effect currently observed in cyclic plasticity of metals. It can also be mentioned that the maximum stress of each test remains constant.
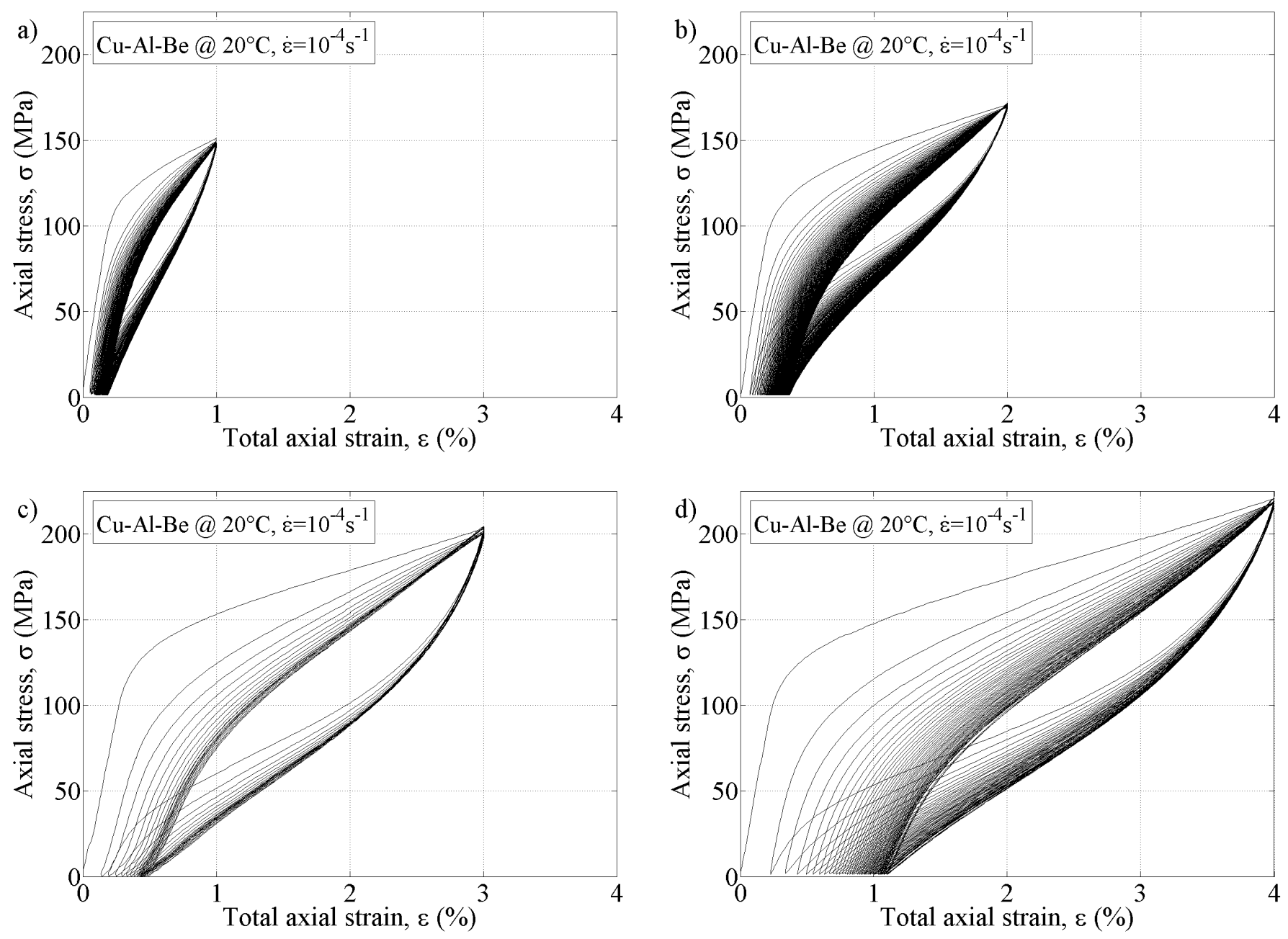

Figure 3: Stress-strain curves under cyclic loading for different strain amplitudes: a) 100 cycles at strain amplitude of $1 \%$, b) 120 cycles at strain amplitude of $2 \%$, c) 20 cycles at strain amplitude of $3 \%$, d) 50 cycles at strain amplitude of $4 \%$. 


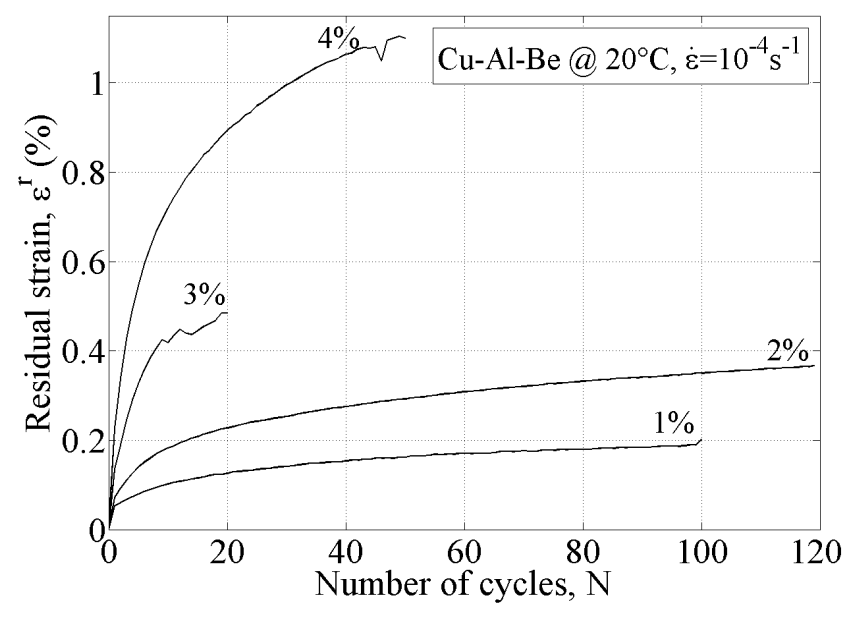

Figure 4: Evolution of residual strain, $\varepsilon^{r}$, versus the number of cycles for the four cyclic tests at strain amplitudes of $1 \%, 2 \%, 3 \%$ and $4 \%$.

\subsubsection{Return point memory effect (RPME)}

A complex loading path (OABCDEF) has been performed to show a particular aspect of SMA mechanical behavior called "Return Point Memory Effect" (RPME). This effect was formulated by Ortin [Ortin (1992)] and is very similar to the "discrete memory" notion of Guelin [Guelin (1980)]. To show this effect, the specimen has been loaded until $4 \%$ strain level (A), then unloaded until $2 \%$ (B), then reloaded until 3\% (C), and reunloaded until 1\% (D), then reloaded until 4\% (E) and finally unloaded until zero stress (F). Figures 5 and 6 show the loading history and the corresponding stress-strain curve, respectively. The RPME concept is based on a set of Memory Point (MP), which are local optima of the stress-strain curve. It can be illustrated with the (OABCDEF) loading path. Along the path $(\mathrm{OA})$, there is no MP because the material is virgin. After the first inversion in the loading direction, the point $\mathrm{A}$ becomes a maximum $\mathrm{MP}$ and is memorized by the material. At the point B, the loading direction is reversed once again. B becomes a minimum MP. After the new inversion of the loading direction at C, C becomes a maximum MP. Subsequently, it can be observed, on one hand, that the path (CD) passes by the minimum MP (B). On the other hand, because the internal loop $(\mathrm{CB})$ is closed, the maximum MP (C) is forgotten and the path (DE) passes by the maximum MP (A) (i.e., $\mathrm{A} \equiv \mathrm{E})$. The internal loop (ED) is then closed, the minimum MP (D) is forgotten. So, the last unloading $(\mathrm{AF})$ does not go by the point (D).

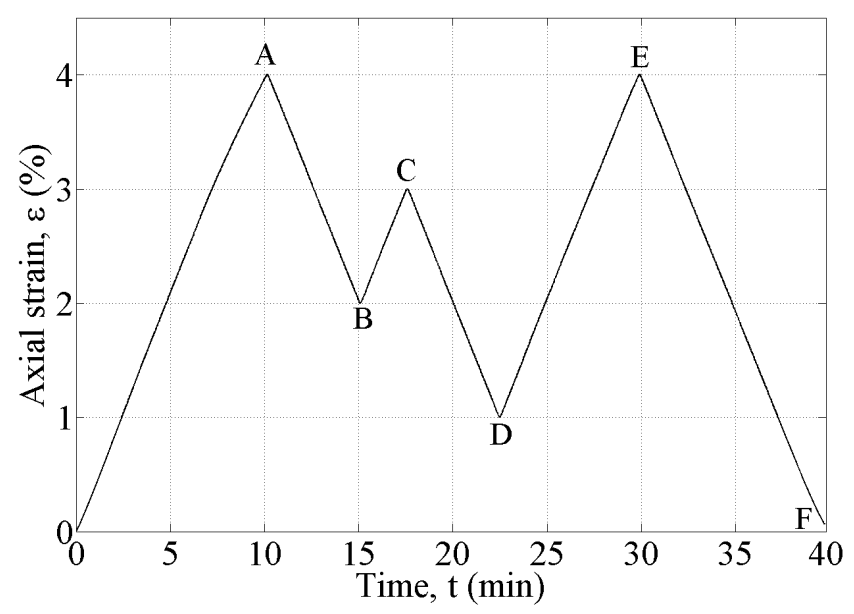

Figure 5: The considered loading history to illustrate the "return point memory effect".

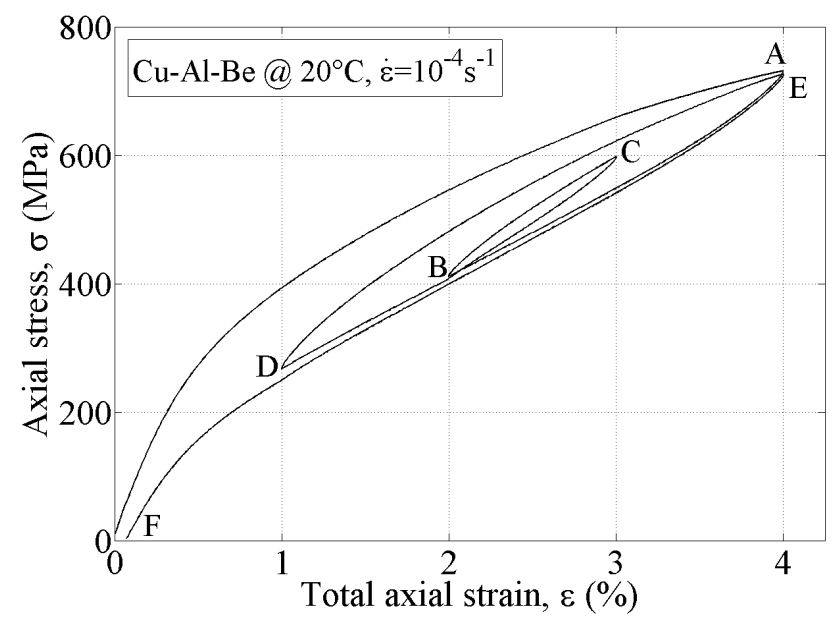

Figure 6: Stress-strain curve of the tensile cyclic test illustrating the "return point memory effect". 


\subsubsection{Cyclic tensile tests under complex loading history}

Two supplementary cyclic tensile tests have been performed to study the evolution of residual strain under more complex loading history. These two tests will be used to validate the constitutive equations proposed further.

The first one consists in applying twelve cycles on a specimen during which the strain amplitude increases progressively with the number of cycles. Figure 7 shows the corresponding stress-strain response. It can be observed that the residual strain increases with the number of cycles (figure 8). This type of test permits also to illustrate the RMPE. Indeed, the reload of each cycle passes by the point at the maximum strain level of the previous cycle. In other words, the point at the maximum strain level of each cycle is a maximum MP for the next cycle.

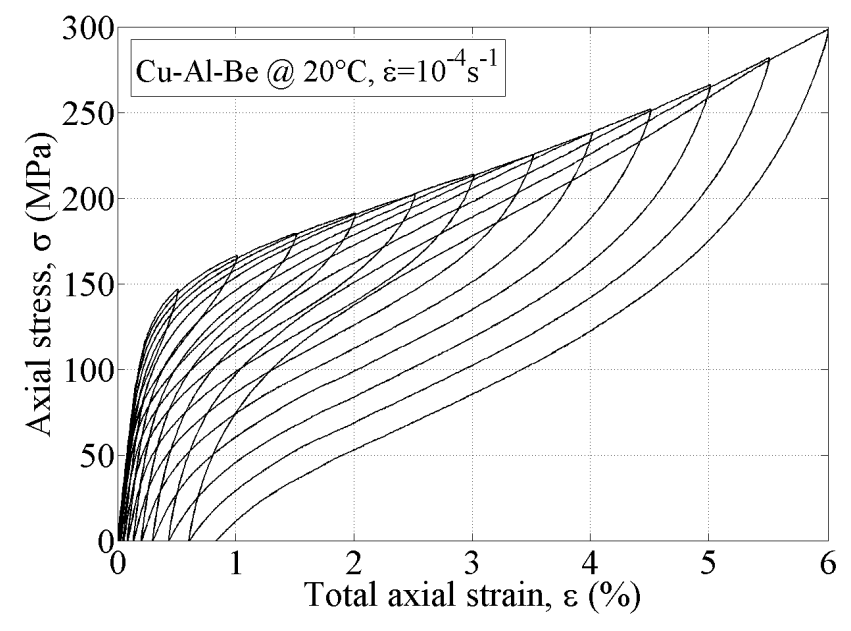

Figure 7: Stress-strain curve under cyclic loading with increasing strain amplitude.

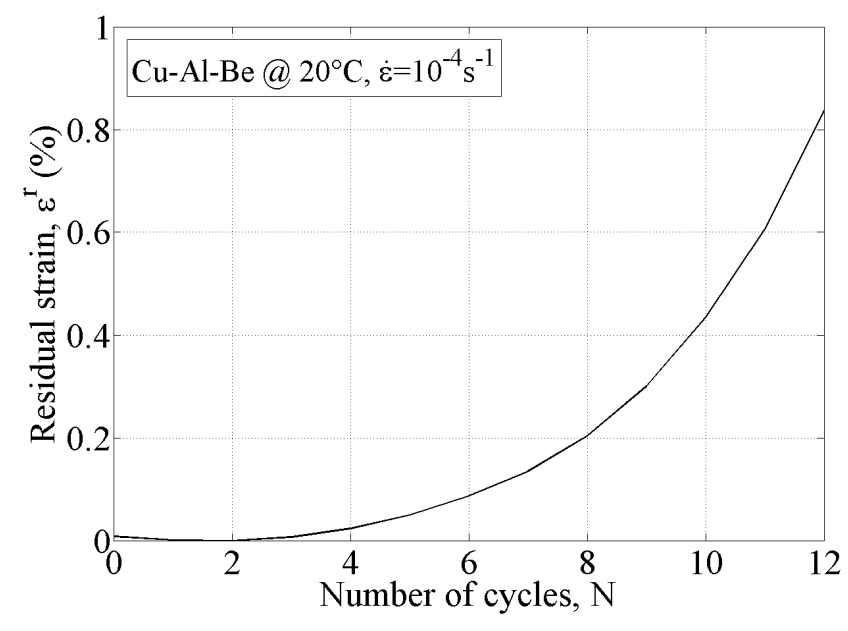

Figure 8: Residual strain evolution during cyclic test with increasing strain amplitude.

During the second test (figures 9 and 10), two sequences constituted of a loading-unloading up to $4 \%$ strain level followed by fifty cycles to $2 \%$, have been performed. Figures 9 and 10 show the corresponding stress-strain response and the evolution of the residual strain with the number of cycles. It can be observed that the residual strain grows quickly during the first cycle at $4 \%$ and more slowly during the cycles at $2 \%$.

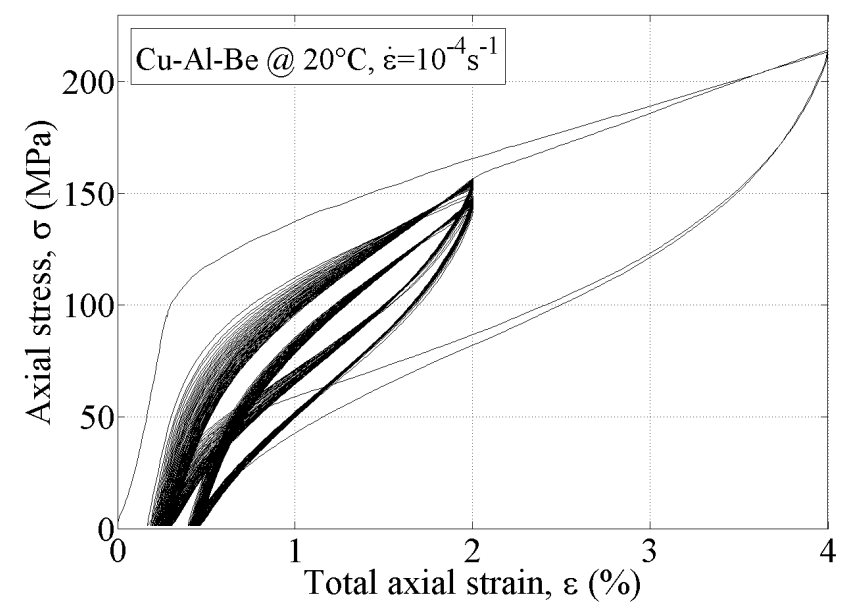

Figure 9: Stress-strain response for the second complex cyclic loading.

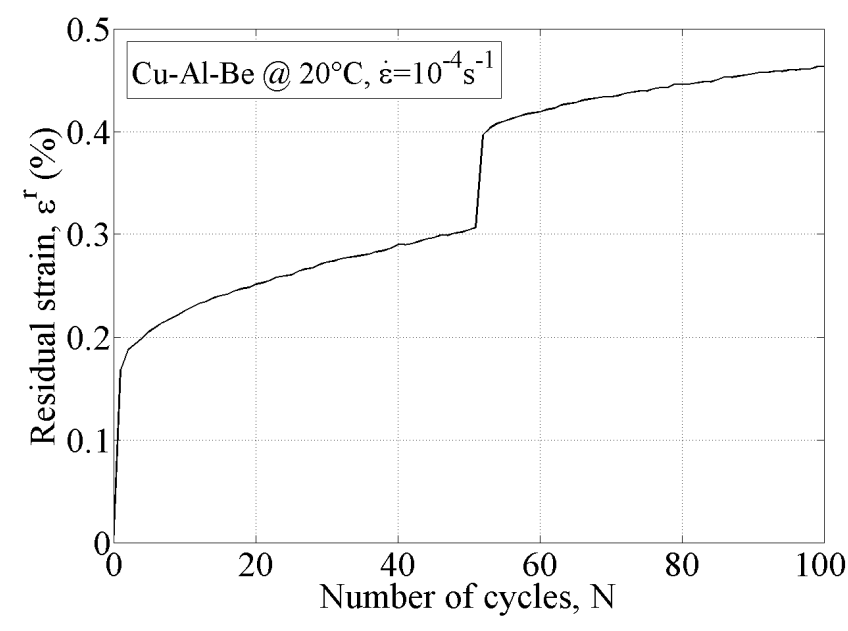

Figure 10: Residual strain evolution during the second complex cyclic loading. 


\subsubsection{Evolution of residual strain during a thermal flash}

The physical origins of the residual strain observed in the mechanical behavior of super-elastic SMA is a controversial question. Indeed, some authors explain it by plasticity due to dislocations motion in the material, some others bring up the residual martensite (i.e., the blocked martensite in the mother phase at macroscopic free stress state).

A simple test is often proposed to give an answer concerning this question. It consists in applying a thermal flash (i.e., heating the specimen up to $200^{\circ} \mathrm{C}$ during a few seconds) to the specimen and observing the evolution of the residual strain. If the residual strain decreases significantly, it can be concluded that their physical origins are the blocked martensite in the austenite phase. Indeed, the short duration of this type of test, and the low level of the temperature during thermal flash do not permit the restoration process of classic plastic strain.

So, after the cyclic test at constant strain amplitude of $4 \%$ (Part 1.2.2), a thermal flash has been applied to the specimen. Figure 11 shows the evolution of the residual strain and the temperature as a function of time. It can be observed that the strain level decreases rapidly until an asymptotic value about $0.25 \%$. So, $77 \%$ of the initial residual strain has disappeared. This experimental observation permits us to assume that residual strain is essentially due to residual martensite. Consequently, no plastic deformation variable will be introduced in the following part concerning the description of constitutive equations.
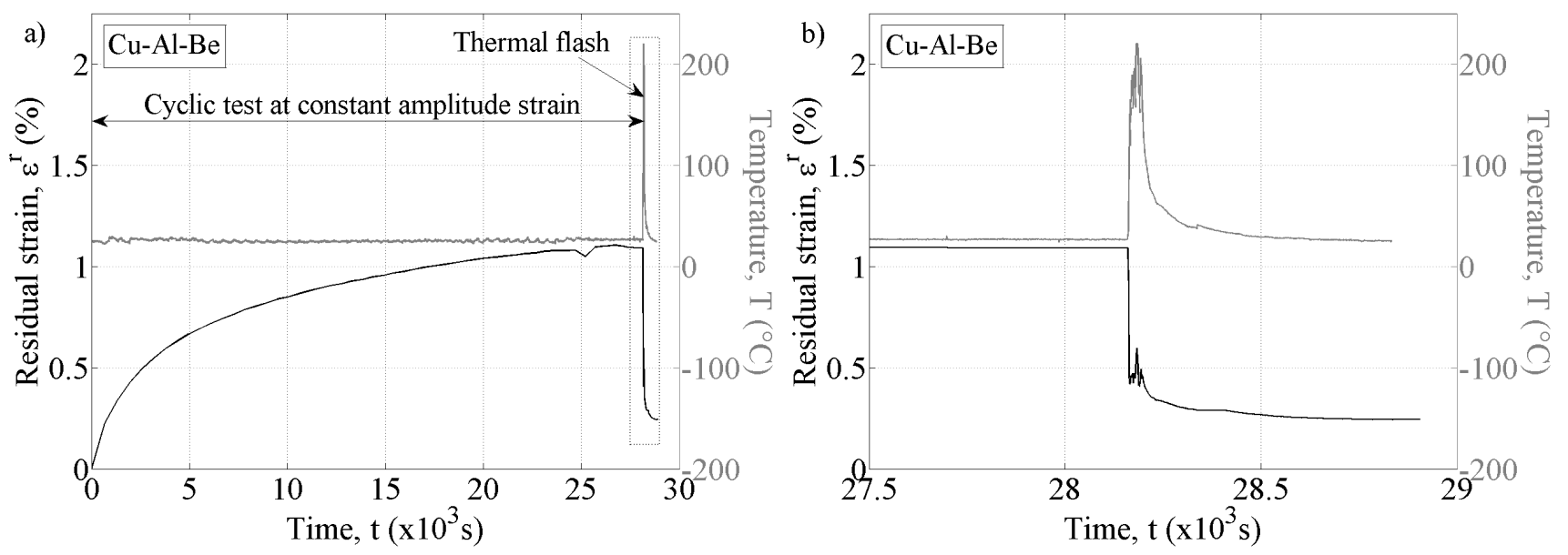

Figure 11: a) Residual strain evolution during the cyclic loading at $4 \%$ strain amplitude, b) followed by a thermal flash. 


\section{3D Model for super-elastic behavior of SMA under cyclic loading}

This part concerns the details of the constitutive equations of a new 3D macroscopic model able to reproduce all the experimental observations presented in the previous part of this paper. As it has been already mentioned, no supplementary variable (e.g., permanent inelastic strain) will be introduced in the total strain decomposition. So, and contrary to recent propositions ([?]), the residual strain will be obtained by a consequence of the kinetic of the phase transformation (i.e., evolution of the transformation strain). The proposed model is an extension of the Bouvet model ([Bouvet et al. (2004)]). Some essential modifications had to be made in order to permit the description of the residual strain evolution under general cyclic loadings (i.e., loading-unloading, cyclic effect, complex history effect). The model is presented in its 3D version for super-elasticity of SMA under multiaxial non-proportional cyclic loadings.

\subsection{Strain decomposition and definition of internal variables}

The framework of small strains has been assumed in this work. So, the classical decomposition of the total strain, $\notin$, is considered:

$$
\mathbb{E}^{t r}=£-\varepsilon^{e}=£-\mathbb{E}^{-1} \mathbb{W}
$$

where $\varepsilon^{e}$ and $\mathbb{E}^{t r}$ are the elastic and transformation strain, respectively, and $\mathbb{E}$ is the stress tensor. To simplify the problem, the elastic behavior of the two phases (i.e., austenite and martensite) are assumed to be the same and represented by the Hooke fourth order tensor $\mathbb{E}$.

\subsection{Forward and reverse transformation surfaces}

The super-elastic shape memory alloys have a typical hysteretic mechanical behavior in which one two thresholds can be defined: the forward and reverse phase-transformation thresholds. In the developed model, two phase-transformation surfaces representing the two transformation thresholds, have been introduced. The first transformation surface, $f_{1}$, leads the forward phase transformation, while the second one, $f_{2}$, leads the reverse one. The shape of the forward phase transformation surface is given by:

$$
f_{1}=\sigma_{e q}-\left(R(z)+\sigma_{0}^{t}\right) \leq 0 \quad(z<1)
$$

where $R$ characterizes the size of the yield surface, $z$ is the volume fraction of martensite, $\sigma_{0}^{t}$, the yield stress of forward transformation and, $\sigma_{e q}$ is the SMA equivalent stress proposed by Bouvet ([Bouvet et al. (2004)]). It is defined as following:

$$
\sigma_{e q}=g\left(y_{\sigma}\right) \bar{\sigma}
$$

where $\bar{\sigma}=\sqrt{\frac{3}{2} \varsigma: \varsigma}$ is the von Mises equivalent stress with $₫$ the deviatoric stress, $y_{\sigma}=\frac{27 \operatorname{det}(\mathrm{s})}{2 \bar{\sigma}^{3}}$ is the third invariant of the stress tensor and $g(y)$ is a function making it possible to modify the shape of transformation surface taking into account the asymmetry between tension and compression (figure 12):

$$
g(y)=\cos \left(\frac{\arccos (1-a(1-y))}{3}\right)
$$

where $a$ is a material parameter permitting to fit the tension-compression asymmetry. This definition of equivalent stress yields to a convex criterion for all values of a varying from 0 to 1 ([Bigoni et al. (2004)]). When $a$ equals to 0 the criterion is the same as the von Mises criterion and when $a$ equals to 1 , the criterion presents its maximal tension-compression asymmetry. The value of $a$ is determined using only the yield stresses in pure tension, $\sigma_{0}^{t}$, and in pure compression, $\sigma_{0}^{c}$, as the solution of:

$$
a=\frac{1-\cos \left(3 \arccos \left(\frac{\sigma_{0}^{t}}{\sigma_{0}^{c}}\right)\right)}{2}
$$

One of the modification made to the model of Bouvet ([Bouvet et al. (2004)]) is the shape of the reverse phase transformation surface, $f_{2}$, which is not any more a straight line but the same shape as the forward 
phase transformation surface, $f_{1}$ (figure 12). Conserving the initial shape of $f_{2}$ (straight line) was at the origin of the inconsistency of the model for some cyclic loadings. In the new formulation, the same shape for $f_{2}$ and $f_{1}$ has been adopted. So, the shape of reverse phase transformation surface is given by:

$$
f_{2}=\overline{\mathbb{U}-\mathbb{X}} g\left(y_{\sigma-X}\right)-\left(R+\sigma_{0}^{t}\right) \leq 0 \quad(z>0)
$$

where the tensor $\mathbb{X}$ locates the center of the reverse phase transformation surface, $f_{2}$ (figure 12 ).

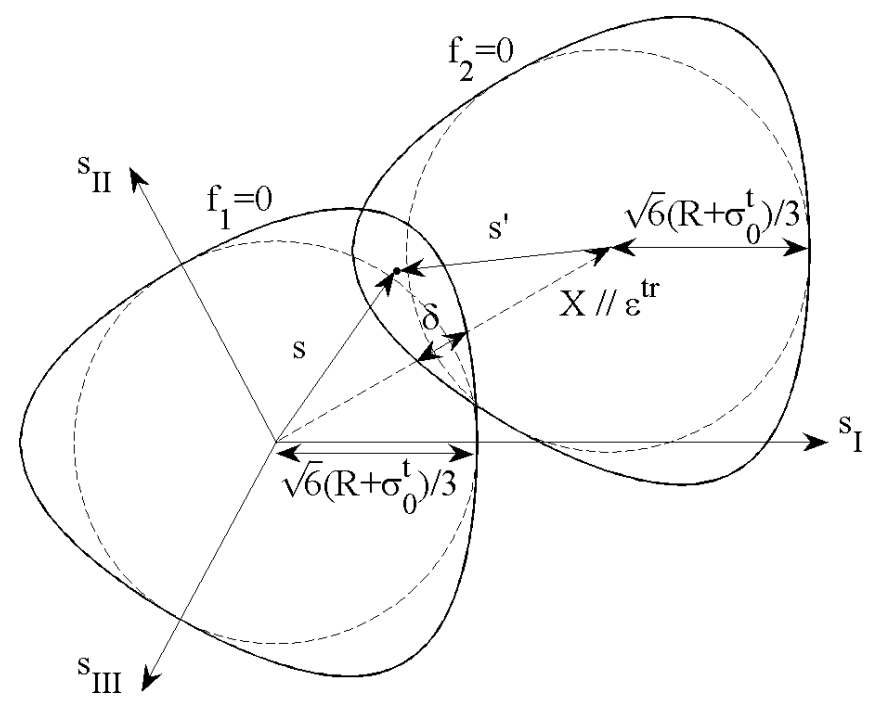

Figure 12: forward, $f_{1}=0$, and reverse, $f_{2}=0$, phase transformation surfaces (von Mises equivalent stress in dashed line).

\subsection{Martensite volume fraction}

The martensite volume fraction is noted $z \cdot z=0$ and $z=1$ define the purely austenitic and martensitic state of the SMA, respectively. The martensite volume fraction is related to the transformation strain, $\varepsilon^{t r}$, by:

$$
z=\frac{\varepsilon_{e q}^{t r}}{\gamma}
$$

where $\gamma$ is a material parameter corresponding to the maximum transformation strain and $\varepsilon_{e q}^{t r}$ is the SMA equivalent transformation strain defined by Bouvet ([Bouvet et al. (2004)]):

$$
\varepsilon_{e q}^{t r}=\overline{\varepsilon^{t r}} \frac{g\left(-y_{\varepsilon}\right)}{g(-1)}
$$

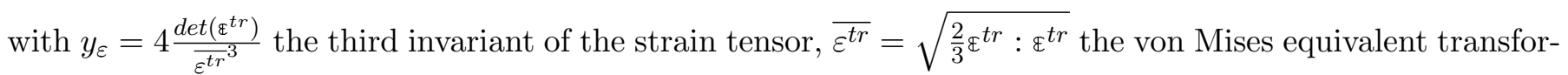
mation strain and function $g$ is defined by equation 4 . The relation between martensite volume fraction and the equivalent transformation strain (equation 7) has been proposed initially by Vacher ([Vacher et al. (1991)]) and has been validated recently under general stress state (i.e., proportional multiaxial loadings, [Taillard et al. (2007)a], and non-proportional multiaxial loadings, [Taillard et al. (2007)b]).

\subsection{Transformation strain evolution}

Two distinct cases have to be considered to describe the transformation strain evolution. These two cases depend on the phase transformation direction (i.e., forward or reverse phase transformation). For the forward phase transformation, the transformation strain rate, $\AA^{\dot{t} r}$, is assumed to be normal to the forward phase transformation surface, $f_{1}=0$, (figure $13 \mathrm{~b}$ ). This hypothesis has been experimentally validated under biaxial 
tension-compression loading ([Bouvet et al. (2002)]) and under tension-torsion loading ([?]). On the other hand, during the reverse phase transformation, the transformation strain rate, $£^{\dot{t}}$, is assumed to be parallel to the transformation strain tensor, $\varepsilon^{t r}$, (figure 13c). This hypothesis can be explained as following: when oriented martensite is created during forward phase transformation, its appearance involves a transformation strain in a certain direction; therefore during its disappearance (reverse phase transformation) the transformation strain rate conserves the same direction as the existing transformation strain tensor. The following equations sum up the two considered cases:

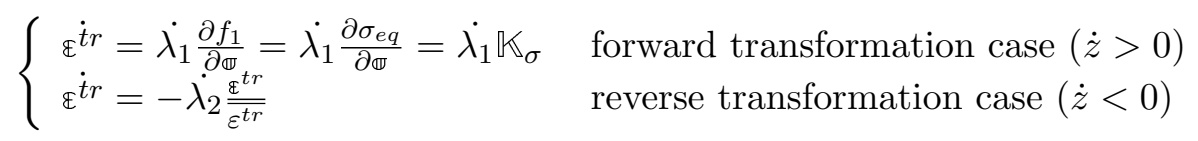

where $\dot{\lambda_{1}}$ and $\dot{\lambda_{2}}$ are the transformation multipliers given by the consistency conditions and have to satisfy the following loading-unloading conditions:

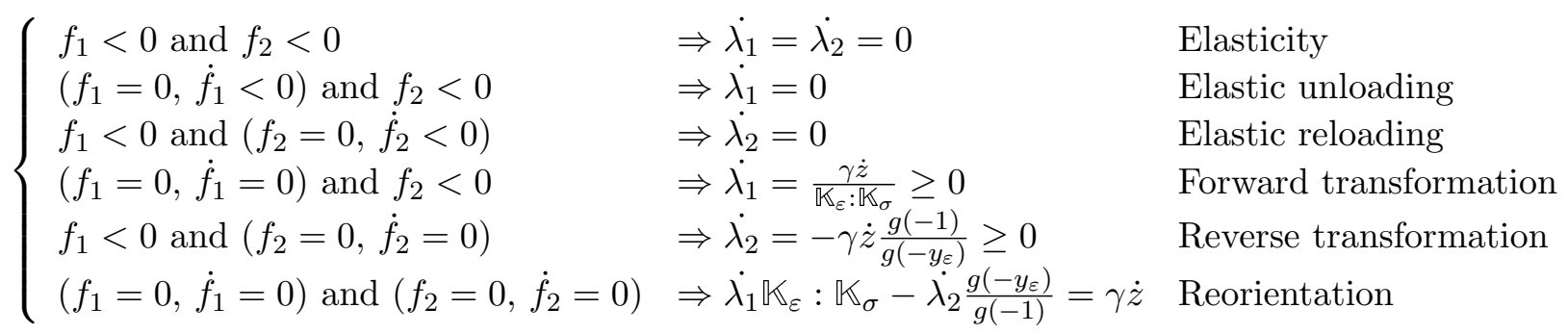

For the biphased material $(0<z<1)$, when the stress state is inside the two transformation surfaces (grayed zone on figure 13a), no transformation happen, the behavior is thus elastic. As when the stress state is on a transformation surface $(f 1=0$ or $f 2=0)$ but moves away from it $(\dot{f} 1<0$ or $\dot{f} 2<0)$, this is called elastic unloading and elastic reloading, respectively.

When the forward phase transformation surface is reached $\left(f_{1}=0\right)$ : if the loading continues, the forward phase transformation surface will grow in order to follow the strain state $\left(\dot{f}_{1}=0\right)$, this is forward transformation (figure 13b).

In the same way when the reverse phase transformation surface is reached $\left(f_{2}=0\right)$ : if the loading continues, the reverse phase transformation surface will move and grow in order to follow the strain state $\left(\dot{f}_{2}=0\right)$, this is reverse transformation (figure 13c).

Finally a particular case happen when both transformation surfaces are reached $\left(f_{1}=0\right.$ and $f_{2}=0$, figure 13d): if the loading continues, both transformation surfaces will move or grow in order to follow the strain state $\left(\dot{f}_{1}=0\right.$ and $\left.\dot{f}_{2}=0\right)$, there is simultaneous forward and reverse transformation. It means that despite the fact that the martensite volume fraction, $z$, remains almost constant, the direction of the transformation strain, $\varepsilon^{t r}$, evolves. This is called reorientation.

\subsection{Forward and reverse transformation surfaces evolution during phase transformation}

The size and the position of the transformation surfaces are defined by $R(z)$ and $\delta(z)$ ( $\mathbb{X}$ being dependent on those two). By varying correctly these variables according to the martensite volume fraction, $z$, it is possible to take into account the return point memory effect (RPME), to reveal a residual deformation and to make it evolve during cycling.

For the return point memory effect, the size and the position of transformation surfaces have to return to there initial value for each loop. And to reveal a residual deformation coming from residual martensite, it is necessary that when stress returns to zero the reverse transformation is incomplete, which can be regulated with the initial position of the reverse phase transformation surface.

\subsubsection{Return point memory effect}

The RPME is respected while defining in a way similar to Bouvet [Bouvet et al. (2004)], the variables $R_{n}^{\min }$, $R_{n}^{\max }, \delta_{n}^{\min }$ and $\delta_{n}^{\max }$ for each loop of loading. They depend on $z_{n}^{\min }$ and $z_{n}^{\max }$ which corresponds to the 

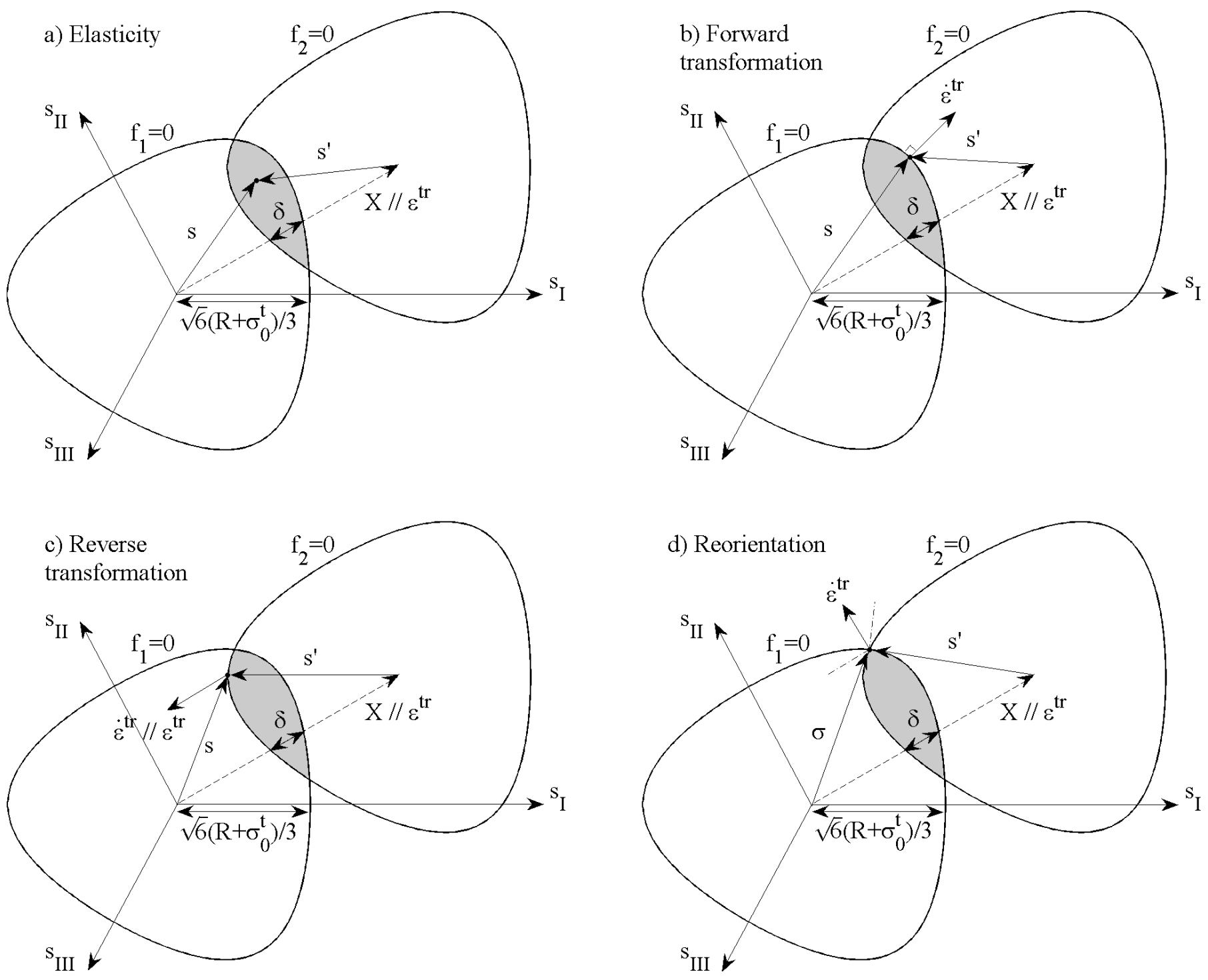

Figure 13: Transformation surfaces for forward, $f_{1}$, and reverse transformation, $f_{2}$, in the case of a biphasic alloy $(0<z<1)$ during: a) the elasticity of a biphasic SMA, b) the forward transformation, c) the reverse transformation, and d) the reorientation of martensite under non-proportional loading.

martensite volume fractions of the high and low memory points of each loop (at unloading and reloading respectively). $n$ is the number of opened loops plus one, it can be calculated according to the number of valid memory points, $m p: n=$ floor $(m p / 2)+2$, with floor $(x)$ the lower or equal integer of $x$. Closed loops and corresponding memory points are completely forgotten.

The tensor $\mathbb{X}$ which determines the center of $f_{2}$, parallel with the transformation strain, $\mathbb{E}^{t r}$, is written:

$$
\mathbb{X}=\left(\left(R(z)+\sigma_{0}^{t}\right)\left(\frac{1}{g\left(y_{\varepsilon}\right)}+\frac{1}{g\left(-y_{\varepsilon}\right)}\right)-\delta(z)\right) \frac{\mathbb{E}^{t r}}{\sqrt{\frac{3}{2} £^{t r}: \mathbb{E}^{t r}}}
$$

with $\delta(z)$ the characteristic size of the elastic range of the biphasic alloy, (figure 13). In order to respect RPME, this size must take again its initial value when a loop is closing, to have the same size as before opening the loop so that the closed loop can be forgotten. A loop may open during a load or an unloading, so $\delta(z)$ must varies between his value before last reloading, $\delta_{n-1}^{\min }=\delta\left(z_{n-1}^{\min }\right)(\dot{z}<0)$, and his value before last 
unloading, $\delta_{n-1}^{\max }=\delta\left(z_{n-1}^{\max }\right)(\dot{z}>0)\left(\delta_{n}^{\max }=\delta\left(z_{n}^{\max }\right)\right.$ for reverse transformation, figure 14a and b):

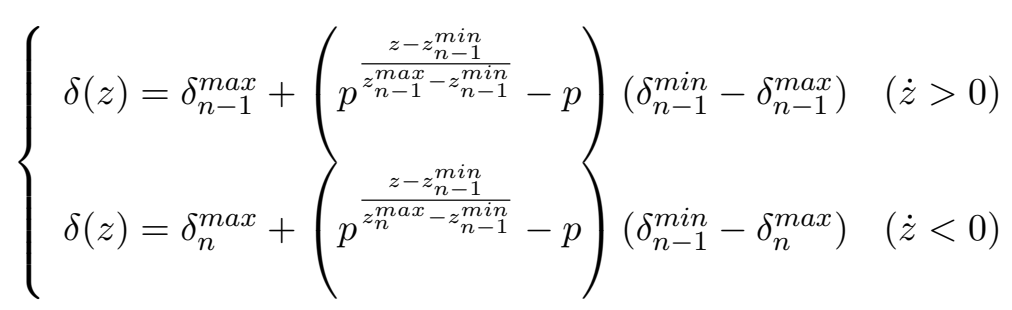

where $p$ is a material parameter. The figure 14a shows in gray the evolution of $\delta(z)$ during a simulation of the memory point loading (part 1.2.3) from point A to point B (unloading), and figure 14b from point B to point $\mathrm{C}$ (reloading).
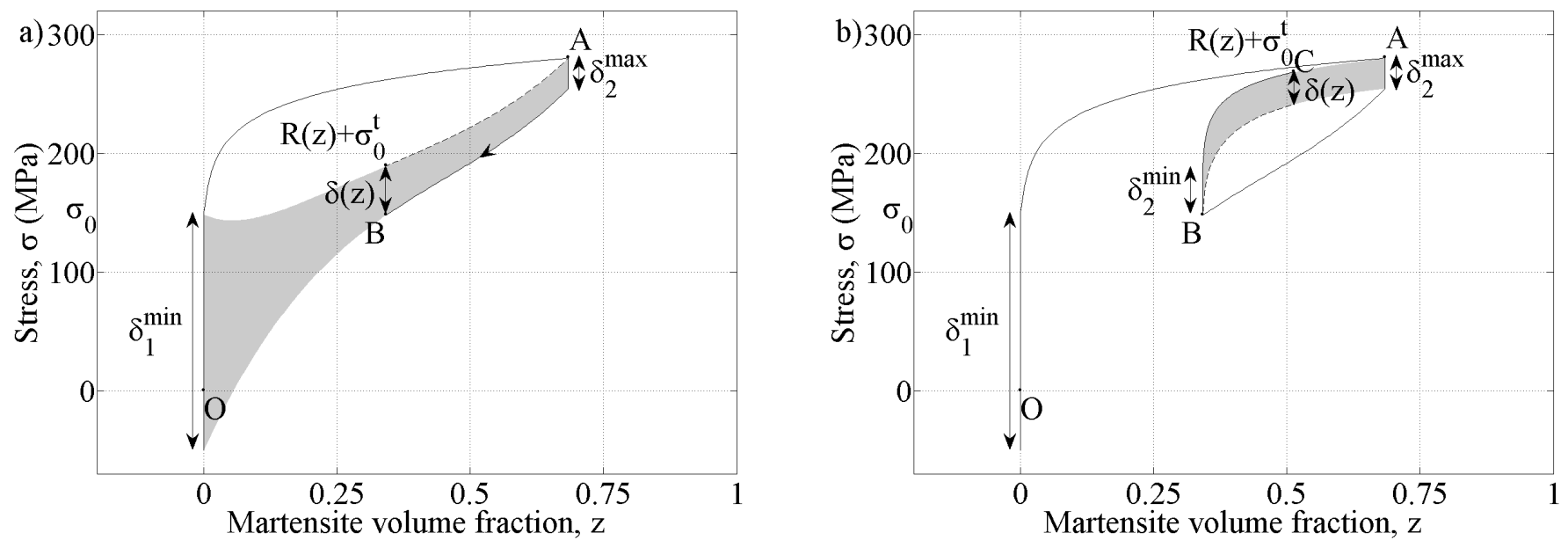

Figure 14: Evolution of $\delta(z)$ during: a) reverse transformation (way A-B) and b) forward transformation (way B-C).

In the same way, the size of transformation surfaces, $R(z)$, must varies between his value before last reloading, $R_{n-1}^{\min }=R\left(z_{n-1}^{\min }\right)(\dot{z}<0)$, and his value before last unloading, $R_{n-1}^{\max }=R\left(z_{n-1}^{\max }\right)(\dot{z}>0)\left(R_{n}^{\max }=\right.$ $R\left(z_{n}^{\max }\right)$ for reverse transformation, figure $15 \mathrm{a}$ and $\left.\mathrm{b}\right)$ :

$$
\begin{cases}R(z)=R_{n-1}^{\min }+g_{1}\left(\frac{z-z_{n-1}^{\min }}{z_{n-1}^{\max }-z_{n-1}^{\min }}\right)\left(R_{n-1}^{\max }-R_{n-1}^{\min }\right) & (\dot{z}>0) \\ R(z)=R_{n-1}^{\min }-\delta_{n-1}^{\min }+g_{2}\left(\frac{z-z_{n-1}^{\min }}{z_{n}^{\max }-z_{n-1}^{\min }}\right)\left(R_{n}^{\max }-\delta_{n}^{\max }-R_{n-1}^{\min }+\delta_{n-1}^{\min }\right)+\delta(z) & (\dot{z}<0)\end{cases}
$$

with $g_{1}$ and $g_{2}$ functions depending on the material, which determine the strain evolution during loading and unloading respectively. During loading the strain evolution is the same as the one of the size of the transformation surface for direct transformation, $R(z)$, but for unloading it is the same as $R(z)-\delta(z)$ (figure 15b), which explains the equation 13 for unloading $(\dot{z}<0)$. The figure 15a shows in the evolution of $R(z)$ during a simulation of the memory point loading (part 1.2.3) from point A to point $\mathrm{B}$ (unloading), and figure $15 \mathrm{~b}$ from point $\mathrm{B}$ to point $\mathrm{C}$ (reloading). 

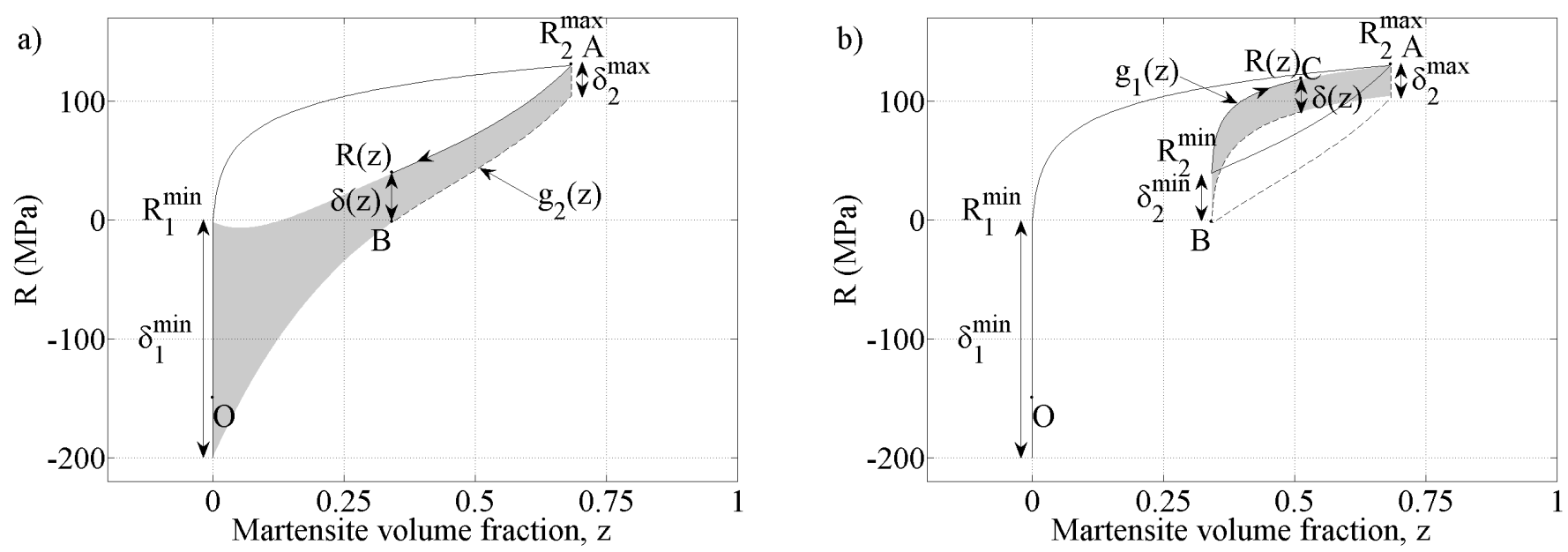

Figure 15: Evolution of $R(z)$ during: a) reverse transformation (way A-B) and b) forward transformation (way B-C).

\subsubsection{Progressive strain under cyclic loading}

In order to introduce a residual strain after unloading, the reverse transformation have to be incomplete when the stress returns to zero. This is possible if the first low dimension of the elastic field of the bi-phased material, $\delta_{1}^{\text {min }}$ (figure 14a), is greater than the yield stress, $\sigma_{0}^{t}$. Indeed the return point for reverse transformation is then at a negative stress, so when unloading to null stress it remains a residual strain, $\varepsilon^{r}$ (figure 16).

To take into account the cycling effect which results in a growth of the residual strain, $\delta_{1}^{\min }$ have to grow with cycles. Indeed bigger $\delta_{1}^{\min }$ is, bigger is the residual strain, $\varepsilon^{r}$ (figure 16). So we defined the cumulated transformation, $t r$, which grows when occurs forward or reverse transformations and thus

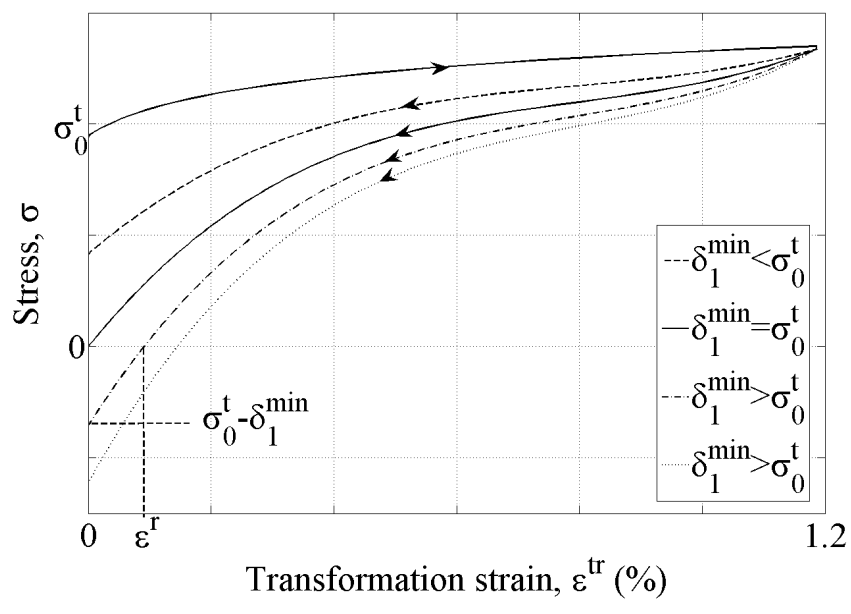

Figure 16: The influence of $\delta_{1}^{\text {min }}$ on the residual strain. with the cycles :

$$
t r=\int \frac{\left|d \varepsilon_{e q}^{t r}\right|}{\gamma}
$$

by varying $\delta_{1}^{\min }$ according to $t r$ :

$$
\delta_{1}^{\text {min }}=\Delta R_{m}\left(1-e^{-b\left(t r+t r_{0}\right)}\right)
$$

the residual strain will have the same behavior (increasing with saturation). But this will give the same behavior for any loading amplitude.

\subsubsection{Progressive strain under complex loading history}

Some modification are needed in order to correctly simulate loadings with various and alternate amplitudes. Loadings at constant amplitude can be simulated with $\delta_{1}^{\min }$ depending on the amplitude:

$$
\begin{gathered}
\delta_{a c}^{\min }=\Delta R_{c}(\Delta z)\left(1-e^{-b\left(t r+t r_{0}\right)}\right) \\
\Delta R_{c}(\Delta z)=A e^{B \Delta z+C}
\end{gathered}
$$




$$
\Delta z= \begin{cases}z-z_{n-1}^{\min } & (\dot{z}>0) \\ z_{n}^{\max }-z & (\dot{z}<0)\end{cases}
$$

But this will not be sufficient to simulated loadings with alternate amplitudes. Indeed the amplitude change will leads to a brutal change or even a decrease of $\delta_{1}^{\text {min }}$, which we do not observe during the tests. So the variation of $\delta_{1}^{\min }$ must depend on the difference between $\delta_{a c}^{\min }$ calculated previously for a constant amplitude and the current value of $\delta_{1}^{\text {min }}$ :

$$
\begin{gathered}
\delta_{1}^{\dot{m i n}}=\Delta R b e^{-b\left(t r+t r_{0}\right)} \dot{t r} \\
\Delta R=\Delta R_{c}(\Delta z) e^{\frac{\delta_{a c}^{\text {min }}+\delta_{1}^{\text {max }}-\delta_{1}^{\text {min }}}{D}}
\end{gathered}
$$

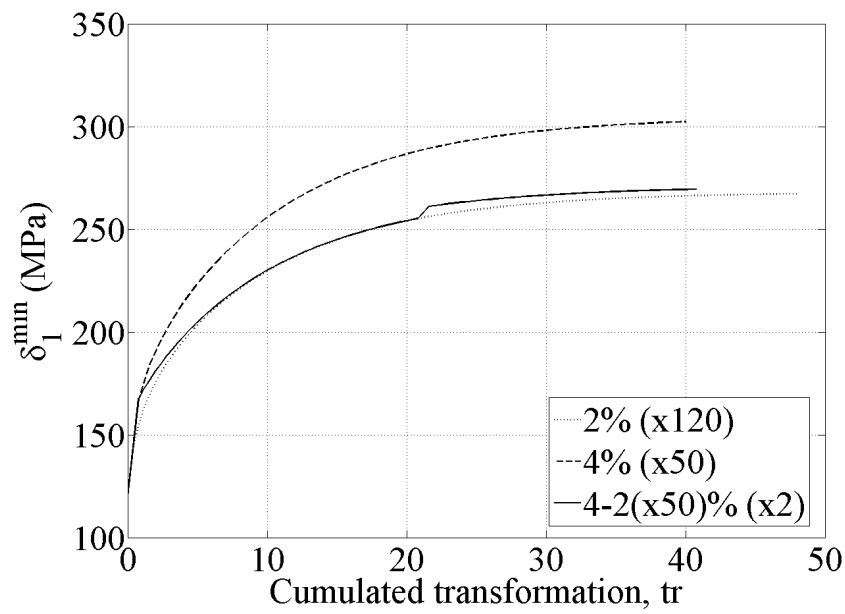

Figure 17: Evolution of $\delta_{1}^{\text {min }}$ during the simulation of a $2 \%$ and $4 \%$ strain amplitude loading, compared with the one of twice a cycle to $4 \%$ of strain amplitude followed by 50 cycles to $2 \%$ of strain amplitude loading (figure 9).

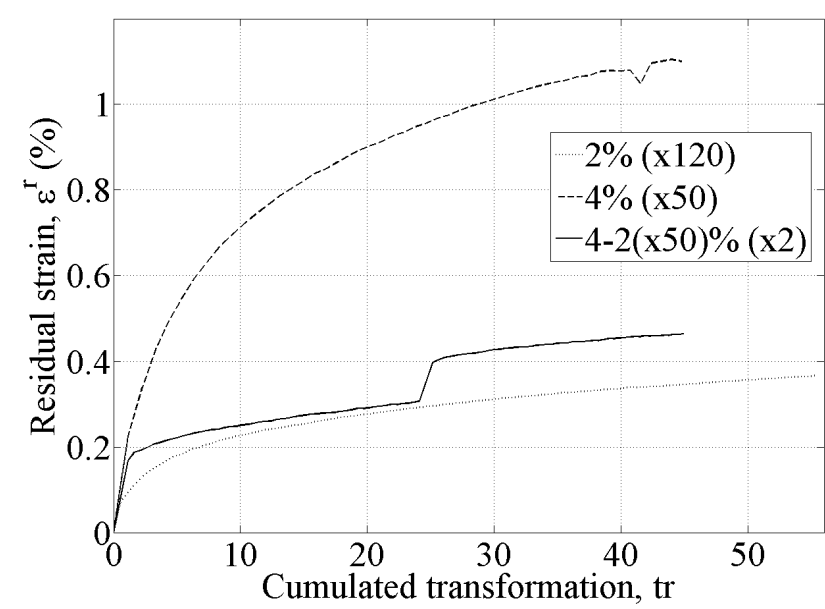

Figure 18: Evolution of the residual strain, $\varepsilon^{r}$, during tests with same loadings. 


\section{Numerical results}

In this part, the material parameters needed by the model are identified, then simulations are carried out in order to validate the behavior of the model with respect to the tests.

\subsection{Material parameters identification for studied Cu-Al-Be SMA}

The material parameters (table 2) were identified from uniaxial cyclic tensile test. They have been adjusted by feating to the tests curves, the results of the simulation of the cyclic test at $2 \%$ of strain amplitude (figure $3 \mathrm{~b}$ ) using the model developed in part 2. Shape functions for the evolution of $R(z)$ during forward and reverse transformation (equation 13) have also been identified:

$$
\begin{gathered}
g_{1}(z)=\frac{\ln \left(1+\left(n_{1}-1\right) z\right)}{\ln \left(n_{1}\right)} \\
g_{2}(z)=\frac{1}{1+n_{21}}\left(1+n_{21} \frac{\ln \left(1+n_{22} z\right)}{\ln \left(1+n_{22}\right)}-\frac{\ln \left(1+n_{23}(1-z)\right)}{\ln \left(1+n_{23}\right)}\right)
\end{gathered}
$$

The stress-strain curve (figure 19) and the evolution of the residual deformation (figure 21) of the simulation are thus well reproduced to the experimental results (figure 20 and 21).

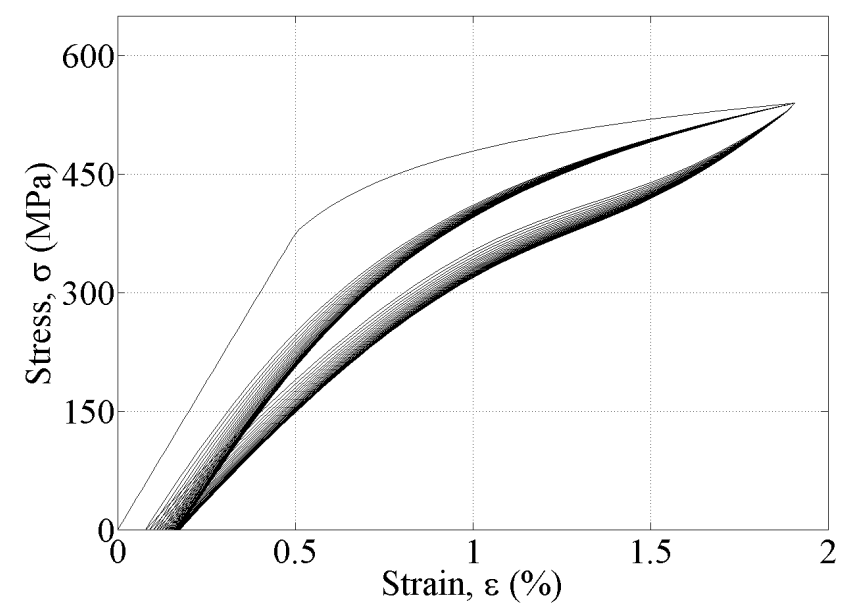

Figure 19: Simulation of the cyclic tensile loading at $2 \%$ of strain amplitude.

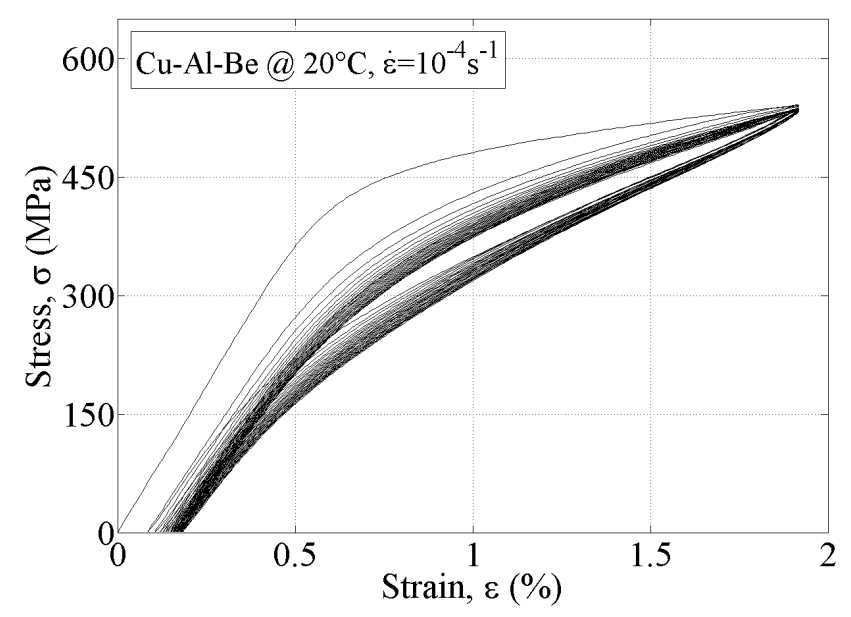

Figure 20: Experimental curve of the cyclic tensile test at $2 \%$ of strain amplitude used to identified the material parameters.

\subsection{Simulation of multiaxial non-proportional cyclic loading}

The figure 23 shows the simulation of a multiaxial non-proportional cyclic loading by the model. The path is a square in the plan $\left(\sigma_{1} ; \sigma_{2}\right)$. The results are similar to the experiments carried out by [Bouvet et al. (2004)] (for the first cycle). Experimental results of multiaxial non-proportional cyclic loadings would make it possible to validate the numerical results. 


\begin{tabular}{lr}
\hline$E(\mathrm{GPa})$ & 75 \\
$\gamma$ & $5.85 \%$ \\
$\sigma_{0}^{t}(\mathrm{MPa})$ & 360 \\
$\Delta R_{m}(\mathrm{MPa})$ & 3.4 \\
$\delta_{0}(\mathrm{MPa})$ & 5 \\
$b$ & 0.3 \\
$t r_{0}$ & 3.75 \\
$a$ & 0.7 \\
$p$ & $10^{-5}$ \\
$n_{1}$ & 81.2 \\
$n_{2}$ & 2 \\
\hline
\end{tabular}

Table 2: Material parameters for this $\mathrm{Cu}-\mathrm{Al}-\mathrm{Be}$ SMA at room temperature.

\subsection{Simulation of proportional cyclic loading}

The figure 22 shows the simulation of a proportional cyclic loading by the model.

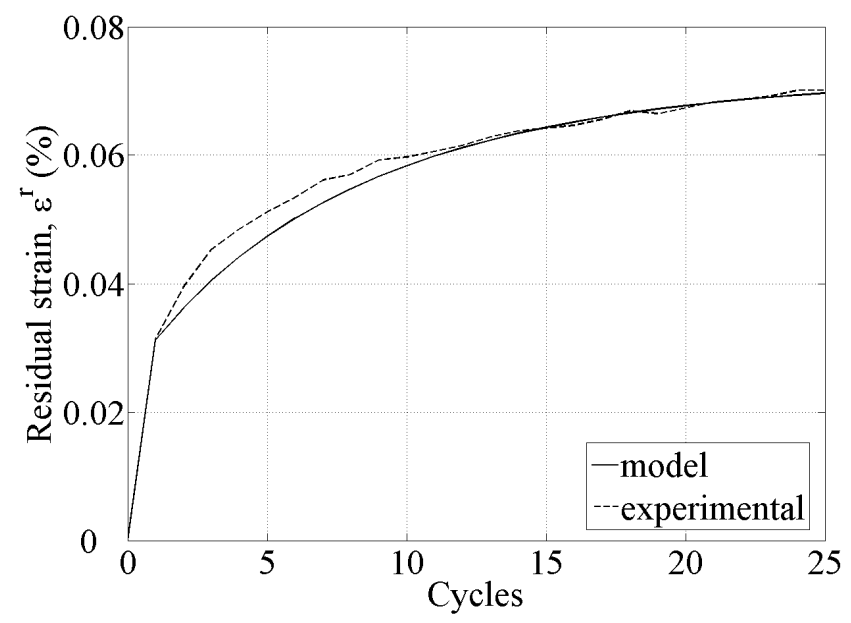

Figure 21: The evolution of the residual strain, $\varepsilon^{r}$, with cycles is also identified with the experimental one.

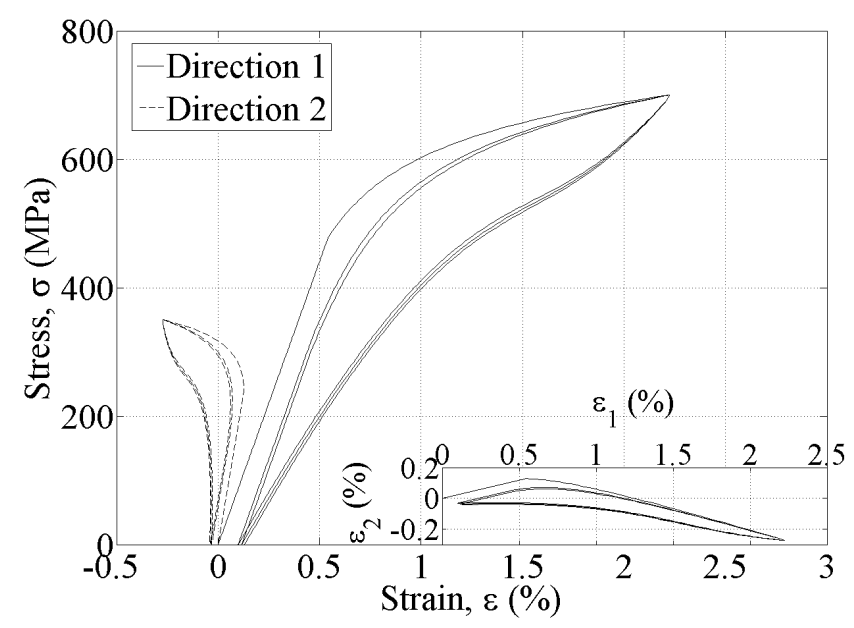

Figure 22: Simulation of a cyclic proportional loading. 


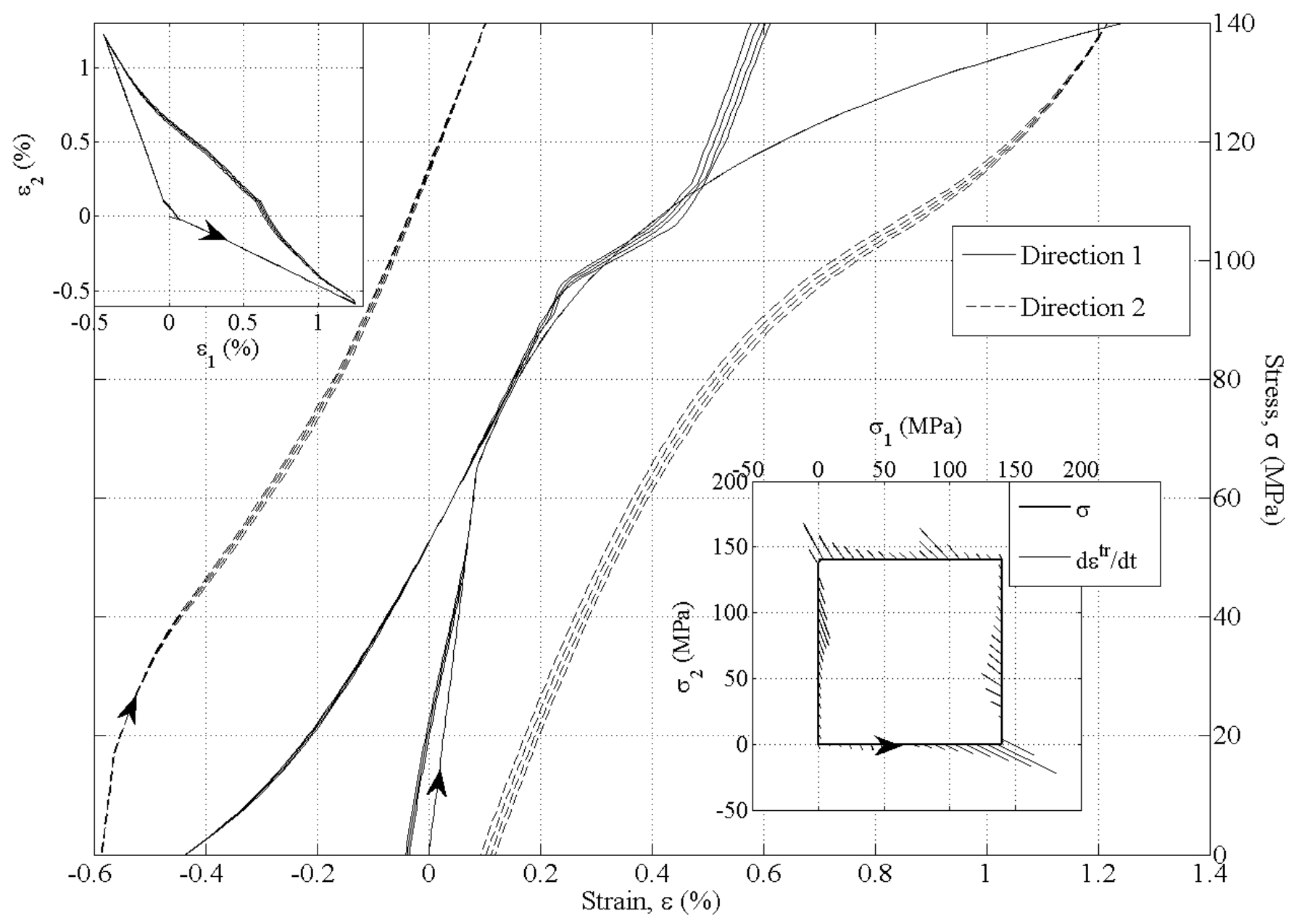

Figure 23: Simulation of a cyclic multiaxial non-proportional loading. 


\section{Conclusions}




\section{References}

[Aurichio et al. (2007)] Aurichio, F., Reali, A., Stefanelli, U. 2007 A three dimensional model describing stress-induced solid phase transformation with permanent inelasticity. Int. J. of Plasticity 23 207-226

[Bigoni et al. (2004)] Bigoni, D., Piccolroaz, A. 2004 Yield criteria for quasibrittle and frictional materials. Int. J. Sol. Struc. 41 11-12 2855-2878

[Bouvet et al. (2002)] Bouvet, C., Calloch, S., Lexcellent, C. 2002 Mechanical behavior of a Cu-Al-Be shape memory alloy under multiaxial proportional and nonproportional loadings. J. Eng. Mat. Tech. 124 112-124

[Bouvet et al. (2004)] Bouvet, C., Calloch, S., Lexcellent, C. 2004 A phenomenological model for pseudoelasticity of shape memory alloys under multiaxial proportional and nonproportional loadings. Eur. J. of Mechanics A/Solids 23 37-61

[Calloch et al. (2002)] Calloch, S., Bouvet, C., Hild, F., Doudard, C., Lexcellent, C. 2002 Analysis of mechanical behavior and in-situ observations of $\mathrm{Cu}$-Al-Be SMA under biaxial compressive tests by using DIC. Proc. SPIE, Third International Conference on Experimental Mechanics, Xiaoping Wu; Yuwen Qin; Jing Fang; Jingtang Ke; Eds. 4537 83-86

[Calloch et al. (2006)] Calloch, S., Taillard, K., Arbab Chirani, S., Lexcellent, C., Patoor, E. 2006 Relation between the martensite volume fraction and the equivalent transformation strain in shape memory alloys. Mater. Sci. Eng. A 438-440

[Lagoudas et al. (2004)] Lagoudas, D.C., Entchev, P.B. 2004 Modeling of transformation-induced plasticity and its effect on the behavior of porous shape memory alloys. Part I: constitutive model for fully dense SMAs. Mech. Mat. 36 865-892

[Entchev et al. (2004)] Entchev, P.B., Lagoudas, D.C. 2004 Modeling of transformation-induced plasticity and its effect on the behavior of porous shape memory alloys. Part II: porous SMA response. Mech. Mat. $36893-913$

[Gall et al. (2002)] Gall, K., Maier, H.J. 2002 Cyclic deformation mechanisms in precipited NiTi shape memory alloys. Acta Materialia 50 4643-4657

[Guelin (1980)] Guelin, P. 1980 Remarques sur l'hystérésis mécanique. J. Méc. 19(2) 217-247

[Montecinos et al. (2006)] Montecinos, S., Moroni, M.O., Sepulveda, A. 2006 Superelastic behavior and damping capacity of CuAlBe alloys. Materials Science \& Engineering A 419 91-97

[Ohno (1997)] Ohno, N. 1997 Recent progress in constitutive modeling for ratcheting. Materials Science Research Int. 3(1) 1-9

[Ortin (1992)] Ortin, J. 1992 Preisach modeling of hysteresis for a pseudoelastic Cu-Zn-Al single crystal. J. Appl. Phys. 71(3) 1454-1461

[Paiva et al. (2005)] Paiva, A., Savi, M. A., Barbosa Braga, A. M., Calas Lopes Pacheco, P. M. 2005 A constitutive model for shape memory alloys considering tensile-compressive asymmetry and plasticity. Int. J. Sol. Struc. 42 3439-3457

[Predki et al. (2006)] Predki, W., W., Klönne, M., Knopik, A. 2006 Cyclic torsional loading of pseuelastic NiTi shape memory alloys: Damping and fatigue failure. Mater. Sci. Eng. A 417 182-189

[Taillard et al. (2007)a] Taillard, K., Arbab Chirani, S., Calloch, S., Lexcellent, C. 2007 Equivalent transformation strain and its relation with martensite volume fraction for isotropic and anisotropic shape memory alloys. Int. J. Mech. Mater. doi:10.1016/j.mechmat.2007.07.005

[Taillard et al. (2007)b] Taillard, K., ?. 2007 ?. ? ? 
[Tobushi et al. (1995)] Tobushi, H., Lin, P.H., Hattori, T., Mikata, M. 1995 Cyclic deformation of NiTi shape memory alloy. JSME Int. J. 38(1) 59-67

[Vacher et al. (1991)] Vacher, P., Lexcellent, C. 1991 Study of pseudoelastic behavior of polycrystalline SMA by resistivity measurements and acoustic emission. Proc. of ICM VI 6 231-236

[Vincent et al. (2004)] Vincent, L., Calloch, S., Marquis, D. 2004 A general cyclic plasticity model taking into account yield surface distortion for multi-axial ratcheting. Int. J. of Plasticity 20 1817-1850

[Wayman et al. (1999)] Wayman, C., Otsuka, K. 1999 Shape Memory Alloys. Cambridge University Press, Cambridge

[Zaki et al. (2007)] Zaki, W., Moumni, Z. 2007 A 3D model of the cyclic thermomechanical behavior of shape memory alloys. J. Mech. Phys. Solids doi:10.1016/j.jmps.2007.03.011 